\title{
Terminal Ileum Perforation as a Consequence of a Migrated and Fractured Oesophageal Stent
}

\author{
V.M. Reddy C.D. Sutton A.S. Miller \\ Department of General Surgery, Leicester Royal Infirmary, Leicester, UK
}

\section{Key Words}

Oesophageal stent · Complications · Fracture · Migration · Perforation

\begin{abstract}
Covered self-expanding metallic stents are commonly employed to relieve malignant oesophageal obstruction. We report a case of a patient with oesophageal cancer treated by stent insertion and curative chemoradiotherapy with subsequent stent migration to the stomach. The stent fractured with the distal fragment migrating as far as the terminal ileum where it caused perforation of the bowel.
\end{abstract}

\section{Introduction}

Oesophageal carcinoma is often a terminal diagnosis with most cases only presenting with symptoms when the disease is at an advanced stage, by which time curative therapy is improbable [1]. The three-year survival rate is only $20 \%$ and the rate of incidence in the West has increased significantly in recent decades [1]. The most common presenting complaint is progressive dysphagia, which is addressed by relieving the oesophageal obstruction to allow normal feeding. Treatment can involve surgery, radiotherapy, chemotherapy, laser and endoscopic stent insertion, either exclusively or in combination [2].

Radiologically guided endoscopic stent insertion can be employed for symptom relief in palliative cases suffering from malignant oesophageal obstruction or as an adjunct to other treatment. The ease of use and the relative speed with which lumen patency is restored makes stent use appealing in such cases, however complications can occur, including migration, oesophageal perforation, haemorrhage, pain, occlusion and recurrence of dysphagia.

In patients with early or low-stage disease, surgery in combination with chemotherapy and/or radiotherapy offers potential for cure. At present, surgery is the 'gold standard' for curative therapy, however it is clear from cohort studies of patients receiving 
chemoradiotherapy as definitive treatment that there are long-term survivors: of patients receiving definitive chemoradiotherapy, 5-year survival rates of $6.5-49.2 \%$ have been demonstrated, as compared to $23-64.9 \%$ in patients having chemoradiotherapy and complete resection [3-7]. It is yet to be established how chemoradiotherapy alone compares to surgery in terms of curative potential because as yet there are no completed randomised controlled trials [3].

In patients undergoing definitive chemoradiotherapy and having a stent, migration is highly likely as the tumour bulk recedes. In our case, the patient had a covered metallic oesophageal stent inserted soon after diagnosis and definitive chemoradiotherapy achieving remission. The stent migrated to the stomach, then fractured. The distal fragment progressed throughout the small bowel and perforated the terminal ileum. This is a rare complication of oesophageal stenting in oesophageal cancer patients having definitive chemoradiotherapy. In those who achieve remission, prophylactic removal of a migrated and fractured stent is worthwhile to avoid potential complications as highlighted by this case.

\section{Case Report}

A 79-year-old female with squamous cell carcinoma of the lower oesophagus (T3 N0 M0) diagnosed twelve months previously had a covered self-expanding metallic oesophageal stent (Choostent; Solco Intermed, Seoul, Korea) inserted to relieve her obstruction. She refused surgery and therefore underwent a course of chemoradiotherapy. This successfully reduced the tumour bulk such that six months after insertion, the stent had become loose and migrated to the stomach. At follow-up chest $\mathrm{x}$-ray stent fracture was noted but it was decided to leave it in situ. She subsequently presented three times with dysphagia secondary to oesophageal strictures, which were treated by balloon dilatation on each occasion.

Six months after the migration and fracture had been noted, she presented to the surgical admissions unit complaining of a two-day history of progressive lower abdominal pain and persistent nausea. Examination demonstrated tenderness and fullness of the right iliac fossa. She was tachycardic, pyrexial and had a raised white cell count $\left(12.5 \times 10^{9} / \mathrm{l}\right)$ and C-reactive protein level $(60 \mathrm{mg} / \mathrm{l})$. A plain abdominal radiograph was performed which demonstrated the stent within the stomach, a fragment of stent in the right lower quadrant and loops of dilated small bowel suggestive of small bowel obstruction (fig. 1). A plain erect chest radiograph was unremarkable with no air under the diaphragm. A contrast-enhanced CT scan of the abdomen and pelvis demonstrated additional findings of free air in the peritoneal cavity, sub-acute small bowel obstruction proximal to the right lower quadrant stent fragment with a local perforation and free fluid in the pelvis ( $\underline{\text { fig. } 2}$, fig. 3 ). A midline laparotomy was performed and perforation of the terminal ileum with faeces and pus in the pelvis was demonstrated. A right hemicolectomy was performed and the remaining stent was retrieved through an anterior gastrotomy. Postoperatively the patient recovered and was medically fit for discharge 15 days later.

\section{Discussion}

Self-expanding metallic stents are widely employed to relieve malignant oesophageal obstruction because they are easy to use, relatively safe and effective in allowing patients to consume a normal diet [8]. Stenting allows rapid establishment of patency relative to the alternative therapies, which involve longer periods of treatment, recovery and morbidity. Although covered stents are associated with an increased risk of migration in comparison to non-covered stents, they are believed to be advantageous in patients with malignant obstruction as they stem the inward growth of tumour, thereby slowing re-obstruction [9]. Metallic stents expand to have larger diameters that are more permissive to solid foods and are slower to occlude. Plastic stents are more likely to migrate, as illustrated by Bastos et al., who described a case in whom a plastic stent came 
to be expelled per rectum [10]. Kato et al. reported a technique of endoscopic clipping of the upper branch of the stent to the oesophageal mucosa in 9 patients in whom stent migration was not encountered [11].

Perforation secondary to stent migration is rare and we only identified two reports of this scenario. Henne et al. described a case in whom two stents used to relieve a recurrent malignant oesophageal stenosis migrated and caused perforation at the site of the side-to-side jejunojejunostomy of an earlier Bilroth II [12]. Kim et al. reported a duodenal perforation secondary to a migrated stent [13]. Stent fracture is also a very rare complication. Dogan and Egilmez reported a case in whom the fractured distal segment migrated only as far as the stomach and remained there uneventfully until the patient died [14]. The authors of this report suggest that such a fragment should only be removed if symptomatic. Altiparmak et al. reported a fractured stent that migrated to the stomach and caused a gastrocolic fistula to develop. Endoscopic retrieval methods (using grasping forceps, balloon dilatation catheters and polypectomy snare) were unsuccessful, necessitating gastrotomy [15].

In our case, stent insertion was required to relieve malignant obstruction early prior to a course of definitive chemoradiotherapy. Patients whose disease responds well to chemoradiotherapy are prone to stent migration as the cancer bulk shrinks.

Non-fractured migrated stents can usually be left safely within the stomach. Endoscopic methods of removing migrated stents have been reported, but they carry a considerable risk of complications, such as perforation, and can be technically very difficult and prolonged [16].

\section{Conclusion}

We would advocate the elective surgical removal of fractured oesophageal stents in patients who are in remission having had definitive chemoradiotherapy. This approach would prevent the occurrence of potentially fatal scenarios as illustrated by this case. 


\begin{tabular}{r|l|l|l} 
Case Reports in & $\begin{array}{l}\text { Case Rep Gastroenterol 2009;3:61-66 } \\
\text { D0I: 10.1159/000210542 }\end{array}$ & Published online: April 15, 2009 & $\begin{array}{l}\text { O 2009 S. Karger AG, Basel } \\
\text { ISSN 1662-0631 } \\
\text { www.karger.com/crg }\end{array}$ \\
\hline
\end{tabular}

Fig. 1. Plain abdominal radiograph.

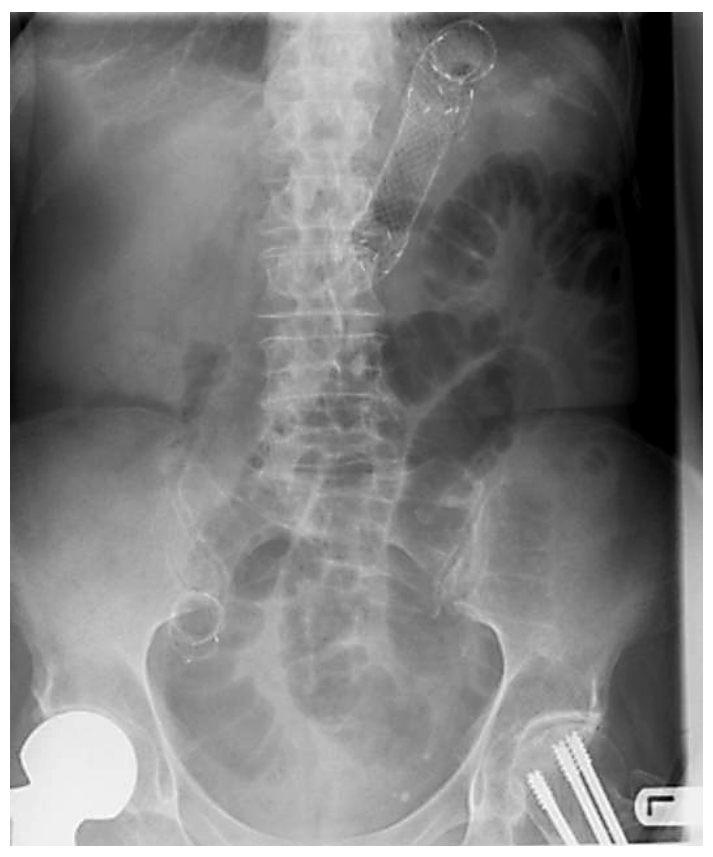

Fig. 2. Contrast-enhanced CT axial view at level T12 demonstrating the stent in the stomach.

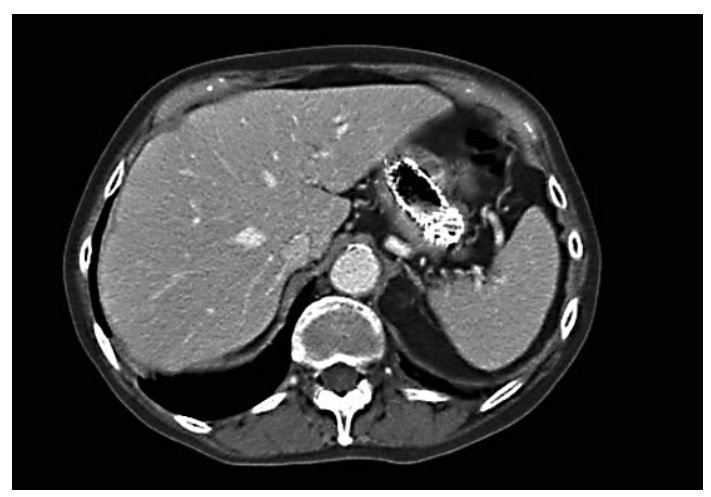


Fig. 3. Contrast-enhanced CT axial view at level S3 demonstrating the stent fragment in the terminal ileum, with localised collection, dilated loops of small bowel, and free air in the peritoneal cavity.

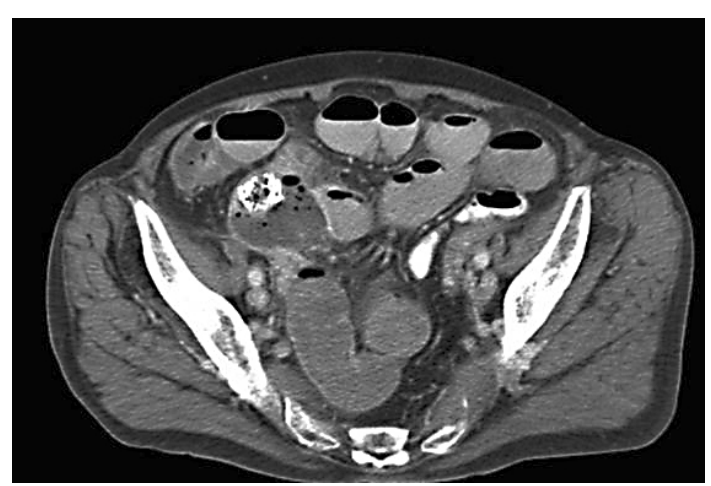




\section{References}

1 Pera M, Manterola C, Vidal O, Grande L: Epidemiology of esophageal adenocarcinoma. J Surg Oncol 2005;92:151-159.

2 Siersema PD, Dees J, van Blankenstein M: Palliation of malignant dysphagia from oesophageal cancer. Rotterdam Oesophageal Tumor Study Group. Scand J Gastroenterol Suppl 1998;225:75-84.

-3 Denham JW, Steigler A, Kilmurray J, Wratten C, Burmeister B, Lamb DS, Joseph D, Delaney G, Christie D, Jamieson G, Smithers BM, Ackland S, Walpole E: Relapse patterns after chemo-radiation for carcinoma of the oesophagus. Clin Oncol (R Coll Radiol) 2003;15:98-108.

-4 Al-Sarraf M, Martz K, Herskovic A, Leichman L, Brindle JS, Vaitkevicius VK, Cooper J, Byhardt R, Davis L, Emami B: Progress report of combined chemoradiotherapy versus radiotherapy alone in patients with esophageal cancer: an intergroup study. J Clin Oncol 1997;15:277-284.

-5 Adams R, Morgan M, Mukherjee S, Brewster A, Maughan T, Morrey D, Havard T, Lewis W, Clark G, Roberts S, Vachtsevanos L, Leong J, Hardwick R, Carey D, Crosby T: A prospective comparison of multidisciplinary treatment of oesophageal cancer with curative intent in a UK cancer network. Eur J Surg Oncol 2007;33:307-313.

-6 Fujita H, Sueyoshi S, Tanaka T, Tanaka Y, Matono S, Mori N, Shirouzu K Yamana H, Suzuki G, Hayabuchi N, Matsui M: Esophagectomy: is it necessary after chemoradiotherapy for a locally advanced T4 esophageal cancer? Prospective nonrandomized trial comparing chemoradiotherapy with surgery versus without surgery. World J Surg 2005;29:25-30.

7 Liao Z, Zhang Z, Jin J, Ajani JA, Swisher SG, Stevens CW, Ho L, Smythe R, Vaporciyan AA, Putnam JB Jr, Walsh GL, Roth JA, Yao JC, Allen PK, Cox JD, Komaki R: Esophagectomy after concurrent chemoradiotherapy improves locoregional control in clinical stage II or III esophageal cancer patients. Int J Radiat Oncol Biol Phys 2004;60:1484-1493.

-8 Cordero JA Jr, Moores DW: Self-expanding esophageal metallic stents in the treatment of esophageal obstruction. Am Surg 2000;66:956-958; discussion 958959.

-9 Morgan R, Adam A: Use of metallic stents and balloons in the esophagus and gastrointestinal tract. J Vasc Interv Radiol 2001;12:283-297.

10 Bastos I, Gomes D, Gregorio C, Baranda J, Gouveia H, Donato A, de Freitas D: An unusual foreign body in the rectum. Hepatogastroenterology 1998;45:15871588 .

-11 Kato H, Fukuchi M, Miyazaki T, Manda R, Faried A, Takita J, Nakajima M, Sohda M, Fukai Y, Masuda N, Tsukada K, Kuwano H: Endoscopic clips prevent self-expandable metallic stent migration. Hepatogastroenterology 2007;54:13881390.

-12 Henne TH, Schaeff B, Paolucci V: Small-bowel obstruction and perforation. A rare complication of an esophageal stent. Surg Endosc 1997;11:383-384.

-13 Kim HC, Han JK, Kim TK, Do KH, Kim HB, Park JH, Choi BI: Duodenal perforation as a delayed complication of placement of an esophageal stent. J Vasc Interv Radiol 2000;11:902-904.

14 Dogan UB, Egilmez E: Broken stent in oesophageal malignancy: a rare complication. Acta Gastroenterol Belg 2005;68:264-266.

15 Altiparmak E, Saritas U, Disibeyaz S, Sahin B: Gastrocolic fistula due to a broken esophageal self-expandable metallic stent. Endoscopy 2000;32:S72.

-16 von Schonfeld J: Endoscopic retrieval of a broken and migrated esophageal metal stent. Z Gastroenterol 2000;38:795-798. 